e-Mosaicos - Revista Multidisciplinar de Ensino, Pesquisa, Extensão e Cultura do Instituto de Aplicação Fernando Rodrigues da Silveira (CAp-UERJ)

ANO 1 - V. 1 - N. 1 - JUNHO 2012 - ISSN: 2316-9303

\title{
NARRATIVAS DE MULHERES GUERREIRAS: \\ Histórias De Vida, Leitura E Escrita Na EJA
}

\author{
Andrea da Paixão Fernandes ${ }^{1}$ \\ Olga Guimarães Germano² \\ Ivana de Oliveira Guedes ${ }^{3}$
}

CAp-UERJ

\section{RESUMO:}

Em uma turma de educação de jovens e adultos (EJA) em fase de alfabetização, composta, exclusivamente, por mulheres, desenvolvemos um projeto de produção de suas autobiografias. Nossa escolha parte do entendimento que temos acerca da importância da construção de práticas de alfabetização e letramento fundamentadas em aspectos que sejam significativos para os sujeitos aprendizes.

Além de possibilitar a elevação da auto-estima dessas mulheres que, por se sentirem excluídas da sociedade, julgam-se incapazes de aprender, o trabalho com as práticas de leitura e de escrita a partir da história oral de cada uma, desperta o prazer de ler e escrever, proporcionando momentos de reflexão e questionamentos acerca do uso da linguagem oral e escrita. Como metodologia, recorremos à leitura de autobiografias de outros sujeitos da EJA. As nar-rativas produzidas pretendiam resgatar memórias dos tempos da infância, da adolescência, do primeiro encontro com a escola e com o mundo do trabalho. No início, as narrativas contemplavam, apenas, momentos recentes de suas vidas, parecendo que não queriam, ou não deveriam, garimpar mais fundo as suas memórias. Precisamos instigá-las a falar tudo de que se lembrassem e como lembrassem e passamos ao registro escrito das histórias narradas. Realizamos, coletivamente, a revisão textual, buscando maior articulação entre a linguagem oral e escrita. Decidimos transformar as narrativas em um livro que, mais do que apenas histórias de vidas, revela-nos que a experiência de vida de cada uma atravessa os limites da coragem e da determinação pela volta à sala de aula para aprenderem, não só a ler e a escrever, mas a se inscreverem, novamente, na roda da vida.

PalaVRas-Chave: histórias de vida - memória - letramento

\section{ABSTRACT:}

In a group of teenagers and adult education (Brazilian 'EJA'), learning to read and write, and composed, exclusively, of women, we developed a project in which they would produce their autobiographies. Our choice was fundamented on our concern that it is important to become literate based on aspects that are significant for the learners. This project rises the selfesteem of those women who used to feel excluded from society and believed they were not able to learn. Consequently, writing their own stories makes them feel good and think over oral and 
e-Mosaicos - Revista Multidisciplinar de Ensino, Pesquisa, Extensão e Cultura do Instituto de Aplicação Fernando Rodrigues da Silveira (CAp-UERJ) ANO 1 - V. 1 - N. 1 - JUNHO 2012 - ISSN: 2316-9303

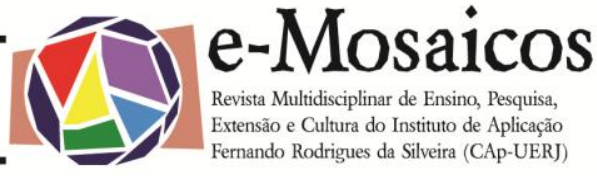

written language. We started our work by reading other EJA learners' autobiographies, whose narratives recall their childhood and teenage, as well as their first school and workday. In the beginning, the learners only wrote about their latest memories, as if they did not want to, or should not, remember the old days. Teachers had to encourage them to speak about their past before they would write. The teachers and the learners reviewed the texts together to reduce the gap between the oral and written language. A book was produced with their texts, which not only show their life experiences, but also their courage and determination to go back to school to learn to read, write, and live again.

KEY-WORDS: life stories - memory - literacy

\section{INTRODUÇÃO}

Aprender a ler e escrever é um desafio a ser superado por muitas mulheres e por muitos homens brasileiros. Fazer isso de forma significativa é um desafio ainda maior. Nesse projeto de extensão universitária de educação de jovens e adultos (EJA), escolhemos resgatar as memórias dos sujeitos envolvidos para que, ressignificando o passado, pudéssemos propor a escrita das suas histórias de vida, tornando-a um exercício menos penoso e mais prazeroso. Entendemos que, tornando esses cidadãos leitoresescritores, ampliamos os diálogos que permitem a construção de muitos novos sentidos e possibilitamos a tomada de posse de uma outra história transformando-os em sujeitos ativos, participantes e autores de suas próprias histórias. Mas por onde começar a puxar os fios desse tecido precioso? 0 que pretendíamos com isso?

\section{DOS FIOS DO PROJETO DE EXTENSÃO AOS REGISTROS DE MEMÓRIAS}

O projeto de extensão universitária $E J A$ - lendo, escrevendo e aprendendo com a sabedoria popular, desenvolvido no Instituto de Aplicação Fernando Rodrigues da Silveira (CAp-Uerj) desde 2005 - tem como objetivos: oferecer aos jovens e adultos das comunidades do entorno do CAp-Uerj oportu- nidades diversificadas de estudos, visando alfabetizar, em sua concepção mais ampla, corroborando para o cumprimento do compromisso social com o resgate do direito à educação, negado, em alguma etapa da vida, a muitos brasileiros; levar os alunos a compreenderem o valor social da leitura e da escrita; formar leitores e escritores a partir da valorização das vivências desses sujeitos e considerando as transformações da sociedade.

Desde o início das nossas atividades, naquele ano, o grupo de estudantes participantes no projeto foi formado, majoritariamente, por trabalhadoras da empresa Construir, responsável pela limpeza e higiene da UERJ, lotadas no CAp-Uerj. No decorrer do processo e reafirmando uma das características da EJA, houve uma oscilação significativa no grupo com a saída de pessoas que eram moradoras das comunidades do entorno e permaneceram, somente, trabalhadoras da Construir. Nesse momento o grupo passa a ser, somente, de mulheres.

Atuavam no projeto, neste momento, duas professoras do Instituto, um bolsista da graduação em Ciências Sociais da UERJ que, posteriormente, por ter concluído o curso, fora substituído por outra bolsista, estudante de Pedagogia da Faculdade de Educação da Baixada Fluminense (FEBF). 
e-Mosaicos - Revista Multidisciplinar de Ensino, Pesquisa, Extensão e Cultura do Instituto de Aplicação Fernando Rodrigues da Silveira (CAp-UERJ) ANO 1 - V. 1 - N. 1 - JUNHO 2012 - ISSN: 2316-9303

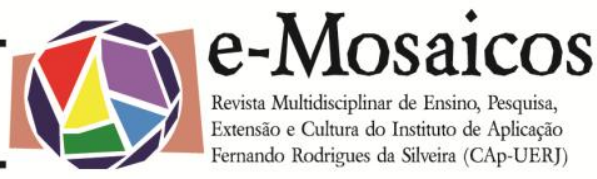

Buscávamos levar o grupo a compreender o valor social da leitura e da escrita, além de investirmos na formação de leitores e de escritores, a partir das experiências e narrativas daquelas mulheres.

Levá-las a falar de si era algo muito difícil. Sobretudo porque representava recordar, por vezes, momentos de grande dificuldade na vida de cada uma delas seja enquanto criança, adolescente, jovem ou adulta. Paradoxalmente, o desejo de escrever suas histórias de vida era latente. Mas, por onde começar? Junto a isso, percebíamos, a cada dia, uma mudança no rosto daquelas mulheres. E quem eram/são elas?

Antonia, Leni, Neuza e Taiçara são as mulheres-trabalhadoras da Construir que estão aqui, nesse texto, como personas e personagens. Mulheres guerreiras, como carinhosamente as intitulamos, que têm várias jornadas de trabalho durante o dia. A primeira delas consiste na realização das tarefas domésticas: cuidar de filhos, arrumar, lavar, passar, cozinhar...; a segunda jornada é a do trabalho no CAp-Uerj: arrumar, lavar, varrer, encerar, faxinar, tirar e colocar móveis no lugar, tirar o lixo; na terceira, participam como estudantes do projeto de extensão universitária EJA - lendo, escrevendo e aprendendo com a sabedoria popular, onde chegam cheias de vida, cabelos molhados, maquiadas, cheirosas e baruIhentas, com uma alegria intensa, qual crianças indo pela primeira vez, à escola.

Há todo um ritual para chegarem à sala de aula. Despem-se de seu papel de trabaIhadoras para vestirem-se de estudantes. Há um sorriso largo e um brilho nos olhos que não deixa dúvidas da importância desse "retorno à escola". Há cadernos novos, estojos com borracha, apontador e lápis que denunciam seus desejos e que significam muito mais do que um simples material. Parece que querem mostrar sua força, pôr à prova suas capacidades e conhecimentos, sentindo-se de novo, parte da sociedade.

Ali, naquele espaçotempo, lemos, escrevemos, ouvimos e falamos. Uma das atividades que merece destaque foi a leitura feita por nós, professoras, do clássico da literatura Romeu e Julieta. Ouvir a história de Romeu e Julieta, inusitada para quase todas e conhecer a vida de Shakespeare, talvez tenha sido um bom início para seduzir, quebrar o cansaço e o medo do novo. Afinal de contas, falar de amor é sempre um convite para falar da vida e para pensar nela. A obra foi lida em capítulos, verdadeiramente saboreados pelos olhares abrilhantados de cada uma daquelas mulheres.

Essa prática despertou ou fez acordar novamente o gosto pela leitura e o prazer de ouvir alguém ler. Muitas começaram a pegar emprestados os livros da biblioteca da sala de aula para levar para casa. Mas, não apenas, liam para si. As histórias eram lidas para seus filhos. Como desejávamos, a "roda" estava lançada - livros circulando para fora dos muros da escola, adentrando suas casas.

Lemos, ainda, histórias de alunos da EJA. Eram autobiografias que, certamente, dialogavam com as expectativas e perspectivas de nossas alunas. Perguntamos, novamente, se elas gostariam de falar um pouco de suas vidas para escreverem depois. Ainda num movimento de tentar romper com a timidez e com as partes de suas histórias individuais que as incomodavam por algum motivo, foram aceitando. Umas mais facilmente. Outras ainda resistindo.

Começaram a narrar. Algumas oralmente. Outras preferiram escrever e, depois, liam para o grupo. Então, entrecortadamente, foram narrando aquilo de que se lem- 
e-Mosaicos - Revista Multidisciplinar de Ensino, Pesquisa, Extensão e Cultura do Instituto de Aplicação Fernando Rodrigues da Silveira (CAp-UERJ) ANO 1 - V. 1 - N. 1 - JUNHO 2012 - ISSN: 2316-9303

bravam. Não havia uma cronologia definida, mas percebíamos que alguns períodos de suas vidas traziam uma dificuldade maior para serem expostos no e para o grupo. Houve muitos silêncios também, bastante significativos e que tanto queriam dizer. Parece que não queriam lembrar-se dos tempos mais remotos, da infância e só falavam das experiências já adultas. No entanto, com nossa ajuda, com perguntas mais diretas, com as respostas de uma e de outra, começaram a se desvelar e a revelar alguns episódios mais marcantes. Será que por que sabiam que iriam escrever depois aquilo que contavam, falavam menos? Será que por que sabiam que o texto seria lido por outras pessoas, isso as incomodava? Era uma forma de proteção, ou de resistência? Ou será que não queriam lembrar mesmo?

A produção das autobiografias tomou corpo. E vida. Foi pequena em tamanho, mas muito grande em ganhos pessoais e coletivos. Após passar o tempo da timidez, belíssimas histórias de vida ganharam as linhas do papel e ficaram registradas por suas próprias autoras e atrizes narrando, também, as histórias da infância, da adolescência e da idade adulta e as relações temporais com a escola, suas idas e vindas marcadas pelas necessidades impostas pelas diferentes situações de vida, conforme podemos perceber nos depoimentos autobiográficos.

Aos seis anos, comecei a estudar numa escola na cidade. Lá aprendi a bordar, fazia ponto cheio e ponto de cruz, mas, quando tinha sete anos de idade, a minha família decidiu vir para o Rio de Janeiro, tentar uma vida nova e fui obrigada a sair da escola. (Antônia)

Aos sete anos fui para a escola, que se chamava Imaculada Conceição. Lá aprendi a ler e escrever, permanecendo até os quinze anos, porque de- pois tive que trabalhar, para ajudar meu pai e minha mãe.

Na minha adolescência, estudava muito, mas nunca deixei de ajudar minha mãe e meu pai. Eu acordava às cinco horas da manhã. Antes de ir para a escola, fazia muitas coisas, como por exemplo, o café para todo mundo, depois ia estudar. (Neuza)

Aos nove anos, fui para a escola, onde aprendi a ler e a escrever, pelo Mobral, porque de dia, eu plantava cana. (Leni)

Minha mãe não pôde me acompanhar na escola, pois ela sempre estava trabalhando. Era pai e mãe. Isso me marcou bastante e hoje eu me desdobro para não deixar meus filhos sem a minha presença. (Taiçara)

\section{VOLTANDO NO TEMPO... LEMBRANÇAS DOS RECENTES REGISTROS AUTOBIOGRÁFICOS}

Os antigos gregos consideravam a memória uma identidade sobrenatural ou divina: era a deusa Mnemosyne, mãe das Musas que protegem as Artes e a História. A deusa Memória dava aos poetas e adivinhos o poder de voltar ao passado e de lembrá-lo para a coletividade. Tinha o poder de conferir imortalidade aos mortais, pois quando o artista ou historiador registra em suas obras a fisionomia, os gestos, os feitos e as palavras de um humano, este nunca será esquecido e, por isso, não morrerá jamais.

Os historiadores antigos colocavam suas obras sob a proteção das musas, escreviam para que não fossem perdidos os feitos memoráveis dos humanos e para que servissem de exemplo às gerações futuras (CHAUÍ, 1995, p. 126).

Após um ano de terem terminado a escrita de suas memórias ao longo do curso, 
e-Mosaicos - Revista Multidisciplinar de Ensino, Pesquisa, Extensão e Cultura do Instituto de Aplicação Fernando Rodrigues da Silveira (CAp-UERJ) ANO 1 - V. 1 - N. 1 - JUNHO 2012 - ISSN: 2316-9303

voltamos a nos encontrar para que revelassem suas emoções e sentimentos dessa escrita, de ainda vê-la impressa e que falassem sobre as aulas que, a maioria, não mais freqüenta.

Com um tempo apertado entre o final do nosso horário de trabalho e o início do delas, entre risos e olhos marejados, afloraram fatos dos quais elas não se lembraram àquela época.

As novas narrativas borbulhavam e se confundiam com o significado das aulas. Este ir- e - vir passeando pelas memórias e pelas aulas que se interpenetravam como se elas não pudessem separar uma coisa da outra, sugerem que isto aconteceu porque foi ali, provocadas por nós, que tiveram tempo para parar e se fixar no passado, recordando o que conseguiam. Se tivéssemos mais tempo, com certeza, elas teriam muito mais a narrar. Então, poderiam escrever outra história, também autobiográfica, que se somaria a essa. Quem sabe... um novo projeto com esse velho grupo de muIheres que luta, sonha, luta...

Izquierdo (2004) nos diz que só lembramos porque esquecemos e que "esquecemos para poder pensar, e esquecemos para não ficar loucos; esquecemos para poder conviver e para poder sobreviver" (op. cit., p.22). Juntamos a isso, a afirmação de Bosi (1994, p. 419): "A força da evocação pode depender do grau de intenção que envolve". Acreditamos que, por isso, também, nem tudo é recuperado.

A emoção que fez parte dos encontros em sala de aula se repetia e transborda aqui, em novos registros falando da vida - de suas vidas - e das aulas.

Antônia continua freqüentando as aulas. Continua escrevendo e registrando histórias e ideias.

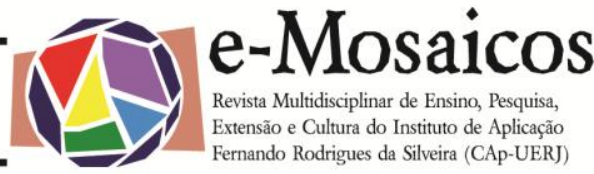

Não tenho nem palavras. Meu pai e minha mãe eram caseiros. Eu tinha cinco, seis anos e acompanhava meu pai no trabalho. Lá se plantava de tudo para vender.

Um dia, andando pelo milharal, colhi uns milhos e fui debulhando pelo caminho. $\mathrm{O}$ dono viu e disse que eu não podia tirar milho não, mas nasceu um do que semeei.

A gente esperava um ano inteiro para ganhar uma boneca de papelão no Natal. (Antônia)

Sobre as aulas, Antônia reconhece a importância para (re)inserção delas na sociedade e nas formas de conviver e dialogar com diferentes sujeitos.

\begin{abstract}
As aulas nos ajudaram muito a ir além, a nos abrir para as pessoas. Agora, falo o que penso, participo mais nos grupos de que faço parte. Eu tinha medo de falar. Ganhei confiança. Venci! (Antônia).
\end{abstract}

As outras três estudantes-autoras não mais frequentam o projeto em função das trajetórias que seguem agora. Mas fazem parte do mesmo grupo de trabalho e convivem, diariamente, conosco, professoras e bolsista do projeto ${ }^{1}$. Suas narrativas, assim como a de Antônia contribuem para a continuidade dos registros autobiográficos já existentes, complementando-os.

Quando ia para a roça com meu pai, gostava de debulhar feijão verde das

\footnotetext{
${ }^{1} \mathrm{~A}$ bolsista do projeto de extensão universitária à época, Ivana Guedes, concluiu a graduação em Pedagogia na Faculdade de Educação da Baixada Fluminense (FEBF-UERJ) e continuou atuando no projeto como voluntária.
} 
e-Mosaicos - Revista Multidisciplinar de Ensino, Pesquisa, Extensão e Cultura do Instituto de Aplicação Fernando Rodrigues da Silveira (CAp-UERJ)

ANO 1 - V. 1 - N. 1 - JUNHO 2012 - ISSN: 2316-9303

vagens para pôr no fogo. Lembro que tinha que carregar saco de macaxeira e de algodão para vender. Doía colher algodão. Feria os dedos. Lembro da casa da farinha. Eu a torrava para fazer beiju. Eu tinha dez, onze anos.

Quando trabalhava no campo, estudava à noite, no MOBRAL. Chegava em casa com o balaio de macaxeira, os pés cheios de barro e só dava tempo de tomar banho, pegar o saco com caderno e lápis e sair correndo para a aula. Minha mãe cozinhava o aipim e eu levava para comer enquanto estudava. Uma colega me apelidou de macaxeira.

Hoje nossos filhos têm tudo e ainda reclamam. O meu brinquedo era o sabugo de milho.

Relembrar o passado causou emoção. A gente nunca esquece, mas não tem tempo de ficar lembrando. As coisas que mais marcaram a vida da gente, as mais sofridas, a gente nunca esquece (Leni).

Como narra Leni, nunca esquecemos dos fatos da nossa vida que nos marcam, porque se constituem como significativos para nós. Enquanto se lembra - e essa ação é individual - seleciona-se o que tem mais significado para si e permite que essas lembranças, ressignificadas, passem a fazer parte da memória de cada um.

As lembranças abrem as portas para o que veio antes e depois. Uma recordação chama outra, compondo uma teia de rememorações mais ou menos singular, cuja textura se alinhava pela maneira como cada memorialista recolhe e amarra as imagens pregressas e busca sua significação (FROCHTENGARTEN, 2005, p. 374).

As portas abertas pelas lembranças es- tão manifestadas pela afirmação de Neuza:

Eu não parava para pensar na minha vida e agora, paro para lembrar.

Meu marido leu minhas memórias e gostou, mas tive que brigar muito com ele para começar a trabalhar.

$\mathrm{O}$ curso, à noite, significou muito para mim (Neuza).

\section{E, também, na afirmação de Taiçara:}

Foi gratificante relembrar o que passamos na vida e isto escrito serviu de lição para meus filhos.

Lembro que passei uma fase difícil e não deixo meus filhos passarem por isso, como, por exemplo, ter só um tênis durante dois anos. Minha mãe era sozinha para tudo e eu me calava para ela não sofrer. Hoje, minha filha diz que se não tiver uniforme novo, não vai para a escola.

As pessoas que lêem o que escrevi, gostam muito. Que isso sirva de experiência para outras pessoas, que seja um aprendizado.

Estudar à noite foi vencer um desafio e a vida é feita de desafios. As aulas também serviram para estreitar as relações de amizade do trabalho (Taiçara).

Ao refletirmos sobre o trabalho desenvolvido com essas mulheres e a arte de contar e recontar histórias, entendemos que tal arte permite manter vivas as heranças e tradições dos sujeitos narradores ou de grupos sociais específicos. Concordamos, então, com Walter Benjamin, quando o autor afirma que:

A narrativa, que durante muito tempo floresceu num meio de artesão 
e-Mosaicos - Revista Multidisciplinar de Ensino, Pesquisa, Extensão e Cultura do Instituto de Aplicação Fernando Rodrigues da Silveira (CAp-UERJ) ANO 1 - V. 1 - N. 1 - JUNHO 2012 - ISSN: 2316-9303

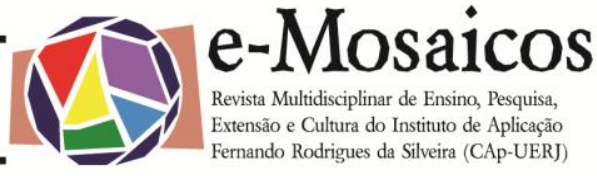

- no campo, no mar e na cidade -, é ela própria, num certo sentido, uma forma artesanal de comunicação. (...) Assim se imprime na narrativa a marca do narrador, como a mão do oleiro na argila do vaso" (BENJAMIN, 1994, p. 205).

Cada uma, a seu modo, foi, artesanal e artisticamente, modelando os contornos de suas vidas, definindo as margens, trabaIhando o tamanho do que queria dizer, a forma e o colorido-algo em preto e branco, algo bem forte e atraente. Foi bom documentar como essas pessoas podem e sabem falar bonito, dar lições de vida e tirar lições da vida. Nós, professoras e bolsista, aprendemos muito com elas também e nosso mestre maior, Paulo Freire, não deixa dúvidas de que "quem forma se forma".

\section{O TEMPO... O QUE É O TEMPO?}

Considerar que o tempo é igual para todas as pessoas, em todo e qualquer lugar, ainda que passe de forma diferente para cada um é, essencialmente, o que constatamos pelas narrativas com as quais vimos trabalhando.

Nosso tempo, "ó tempo rei", com essas alunas-mulheres, medido em horas foi muito pequeno, mas medido em aprendizado de vida, foi infinito. Um, o tempo físico, outro, o tempo psicológico.

\section{(...) Tempo rei, ó tempo rei,}

Transformai as velhas formas de viver

Ensinai-me ó pai o que eu ainda não sei...

(Tempo rei - Gilberto Gil).

Mais tempo tivéssemos, mais instigadas seriam a falar, menos inibidas ficariam, mais cúmplices seríamos. Afinal de contas, lembrar é um exercício. É preciso tempo disponível, desejo, dedicação, investimento para pensar no passado.

O dicionário Aurélio diz que tempo é "a sucessão dos anos, dias, horas etc, que envolve, para o homem, a noção de pas-sado, presente e futuro".

Vidas vi-vidas! Vidas (re)vividas!

Uma das características das histórias dessas mulheres, sofridas, guerreiras de muitas batalhas, é que se limitam mais ao tempo do trabalho do que ao tempo do brincar. E sabemos que a infância é o tempo do brincar, que o único trabalho de uma criança deveria ser a brincadeira, que é através disso que elaboramos nossos conflitos internos e que aprendemos as regras de convivência. A brincadeira faz parte de nosso crescimento e de nossa saúde mental. A elas, esse direito foi negado, como, aliás, à maior parcela de nossa sociedade Mas nisso também são vencedoras, pois deram a volta por cima e, de cabeça erguida, estão aí, na lida diária, proporcionando esse tempo para seus filhos.

Quando Leni fala que "A gente nunca esquece, mas não tem tempo de ficar lembrando" nos reporta a Ecléa Bosi (2004) em seu livro "Memória e Sociedade: lembranças de velhos", quando diz que "o homem ativo (independentemente de sua idade) se ocupa menos em lembrar, exerce menos a atividade da memória, ao passo que o homem já afastado dos afazeres mais prementes do cotidiano se dá habitualmente à refacção do seu passado." (Bosi, 2004, p. 63)

A mesma autora faz, ainda, uma relação com o idoso nas tribos antigas, como guardião do tesouro espiritual:

Quando a sociedade esvazia seu tempo de experiências significativas, 
e-Mosaicos - Revista Multidisciplinar de Ensino, Pesquisa, Extensão e Cultura do Instituto de Aplicação Fernando Rodrigues da Silveira (CAp-UERJ) ANO 1 - V. 1 - N. 1 - JUNHO 2012 - ISSN: 2316-9303

empurrando-o para a margem, a lembrança de tempos melhores se converte em sucedâneo da vida (BOSI, 2004, p. 82).

Em muitas sociedades atuais, o idoso fica com a missão de ser contemplativo, de tudo observar, de guardar, de memorizar. Seu tempo é para isso. Há um tempo de plantar e um tempo para colher. É o que ele faz.

Iván Izquierdo (2004), em seu livro "A Arte de Esquecer", diz que quando somos instigados a pensar, através de perguntas e dicas, evocamos as lembranças mais ocultas e que nossas infâncias guardam episódioschave para o resto de nossas vidas, mas que também perdemos memórias valiosíssimas. A vida consiste em perder neurônios e sinapses e neles podem residir memórias, as quais, por sua vez, se vão junto com essas perdas. Isto ocorre porque os mecanismos que formam e evocam memórias são saturáveis sendo, portanto, impossível para o ser humano guardar na memória tudo o que aconteceu. Na nossa mente há mais esquecimento do que memória e, se não usarmos constantemente nossas sinapses, esqueceremos dos fatos e dos acontecimentos (Izquierdo, 2004).

E porque falamos em história oral, narrativas, lembranças e memórias, não poderíamos concluir este texto sem nos lembrarmos do convite que Eduardo Galeano que nos faz ao indagar, cada vez mais - e sempre - sobre o nosso ponto de partida.

JANELA SOBRE A MEMÓRIA(II)

Um refúgio?

Uma barriga?

Um abrigo onde se esconder quando estiver se afogando na chuva, ou sendo quebrado pelo frio ou sendo revirado pelo vento?

Temos um esplêndido passado pela frente?

Para os navegantes com desejo de vento, a memória é um ponto de partida.

\section{REFERÊNCIAS BIBLIOGRÁFICAS:}

BENJAMIN, Walter. Obras escolhidas. magia e técnica, arte e política - ensaios sobre literatura e história da cultura. v.1. São Paulo: Brasiliense, 1994.

BOSI, Ecléa. Memória e Sociedade: lembranças de velhos. São Paulo: Cia. das Letras, 1994.

FERREIRA, Aurélio Buarque de Holanda. Mini-Aurélio: século XXI - o mini-dicionário da língua portuguesa. Rio de Janeiro: Nova Fronteira, 2000.

FROCHTENGARTEN, Fernando. A memória oral no mundo contemporâneo. In: Revistas Estudos Avançados, 19(55), 2005. p. 367376.

GALEANO, Eduardo. As palavras andantes. Porto Alegre: L\&PM, 1994.

IZQUIERDO, Iván. A arte de esquecer: cérebro, memória e esquecimento. Rio de Janeiro: Vieira \& Lent, 2004.

POLLAK, Michael. Memória, esquecimento, silêncio.In: Revista Estudos Históricos. Rio de Janeiro, v.2, n.3, 1989, p. 3-15.

1 andreaf@uerj.br - Graduada em Pedagogia pela Universidade do Estado do Rio de Janeiro (1999), Mestrado em Educação pela Universidade Federal Fluminense (2003) e Doutorado em Educação pela Universidade Estadual de Campinas (2012). Professora da Prefeitura da Cidade do Rio de Janeiro e Professora Assistente da 
Universidade do Estado do Rio de Janeiro / Instituto de Aplicação Fernando Rodrigues da Silveira - CAp-UERJ. Tem experiência na área de Educação, com ênfase em Educação de Jovens e Adultos, atuando principalmente nos seguintes temas: educação de jovens e adultos, educação ambiental, formação de professores, trabalho e educação, memória e políticas públicas.

2 olgagermano@globo.com - Graduada em Pedagogia pela Universidade Gama Filho (1978) e Especialização em Literatura Infantil e Juvenil pela Universidade Federal Fluminense (1996). Atualmente é Professora Titular da Universidade do Estado do Rio de Janeiro / Instituto de Aplicação Fernando Rodrigues da Silveira - CApUERJ. Tem experiência na área de Educação, com ênfase em Ensino-Aprendizagem.

${ }^{3}$ Licenciada em Pedagogia pela Universidade do Estado do Rio de Janeiro (2006) e Curso Técnico-profissionalizante em Formação de Professores pelo Colégio Estadual Júlia Kubitschek (2001). Tem experiência na área de Educação, com ênfase em Ensino-Aprendizagem. 